\title{
ON THE
}

\section{VALUE OF THE TUBERCLE BACILLUS IN CLINICAL DIAGNOSIS.}

\author{
BX \\ PERCY KIDD, M.D., F.R.C.P., \\ ABSISTANT PHYSICIAN AND PATHOLOGIST TO THE BROMPTON HOSPITAL FOR \\ CONSUMPTION AND DISEASBS OF THE CHEST; \\ AND \\ H. H. TAYLOR, F.R.C.S., \\ ASSISTANT RESIDENT MEDICAL OFFICRR AT THE BROMPTON HOSPITAL FOR \\ CONSUMPTION AND DISEASES OF THE CHEST.
}

Received February 15th-Read May 221nd, 1888.

To some perhaps it may seem superfluous to argue in favour of the value of examining the sputum for tubercle bacilli in all cases of disease of the respiratory organs of uncertain nature. We believe, however, that in England the routine investigation of the sputum in doubtful cases is by no means generally practised. It is not denied that many observers in this country are as fully persuaded of the importance of examining the sputum as are the great bulk of Continental practitioners. But it must be admitted that a not inconsiderable proportion of English medical men still maintain an attitude of distrust towards this method of diagnosis. Considering the very great importance of this question it cannot be said that it has been made the subject of undue discussion. The clinical side of the subject has not been discussed at any of the 
societies in London since 1883, when Dr. Whipham introduced the debate at the Medical Society. At that time Koch's discovery was quite recent, and sufficient time had not elapsed to allow a just estimate to be formed of the value of the sputum test in all its bearings. Since then our knowledge of the subject has been increased and consolidated, though some of the hopes at first expressed have not been realised. Important clinical contributions have been made by Drs. Whipham, Theodore Williams, Gabbett, Hunter Mackenzie, Dreschfeld, Heron, and others in this country, but the number of publications has not been large.

On the other hand, numerous Continental observers have written on this subject. Ehrlich, Balmer and Fraentzel, Leyden, Guttmann, Ziehl, Gaffky, B. Fraenkel, Heitler, Rutimeyer, Frisch, May, Biedert, Germain Sée, Hugueny, D'Espine, and a host of others have brought forward the results of prolonged and laborious investigations. From their observations as well as from those of our own countrymen, it may be affirmed that Koch's bacilli can be detected in the sputum of all cases of phthisis at some period of the disease. Isolated instances have, it is true, been recorded where the bacilli could never be detected in spite of repeated examination, although the necropsy proved that the cases were undoubtedly tuberculous (two cases by Leyden and one by Ziehl).

Such cases are unquestionably worthy of consideration, though their number may be said to be almost insignificant. The statement which was made early in the history of the subject, that a direct proportion exists between the number of bacilli in the sputum and the severity and activity of the disease, is now for the most part admitted to be erroneous. The importance which was assigned to the morphological character of the bacilli, especially the appearance of spores, is no longer insisted upon.

The most disappointing result of all the labour that has been expended on these investigations is the generally 
admitted failure of the sputum test for purposes of prognosis. We may well, however, be thankful if the diagnostic importance of the bacilli has been established upon a firm basis, which we believe to be the fact.

Some clinical authorities perhaps would still dispute this proposition altogether. The general truth of this conclusion, however, appears to be accepted by the immense majority of observers, and may be regarded as abundantly proved by the numerous and careful investigations that have been alluded to.

At the same time it is probably true that there are many physicians who recognise the value of this method of examination in a certain measure, but attach only a modified value to it. It is urged by such critics that the ordinary methods of physical investigation, combined with a careful consideration of clinical facts, are more trustworthy than the sputum test. Now, we have not the slightest intention of disputing the accuracy of this statement for the large majority of cases, where indeed, as it seems to us, the examination of the sputum plays quite an unimportant rôle in diagnosis. But the most experienced observers will be the first to admit that in certain instances, in spite of the most careful physical examination and clinical study, it may be impossible to arrive at a positive conclusion, or at the most the diagnosis may be a matter of probability.

If in such cases we find tubercle bacilli in the sputum we are justified in affirming the existence of tuberculosis; in other words we are enabled to convert an uncertainty, or a conjecture, into a positive assurance. The extreme importance of coming to a definite conclusion in special circumstances, without waiting for the progress of the case to decide, need hardly be insisted upon. A more important objection has been urged by Leyden, who points out that the appearance of the bacilli in the sputum late in the history of a caise may lead us to misinterpret the nature of the affection, and to attach undue importance to what is only an accidental complication of the original 
disease. This is perfectly true, and the warning is a valuable one. But a careful consideration of the history and progress of the disease, together with the physical condition of the patient, will prevent us from attributing too much significance to the detection of the tubercle bacilli in such cases. Illustrations of this fact will be given presently.

The object of the present communication is not to contribute a further proof of the general truth of the proposition which has been stated, but to bring before the Society the results of observations carried on during the last five years, as to the value of the sputum test in those cases alone in which the ordinary methods of diagnosis did not warrant a definite conclusion.

Striking cases have been described by various observers where the detection of tubercle bacilli made a positive diagnosis possible, in the complete absence of physical signs of pulmonary disease, or when the signs were anomalous, but such observations are only to be forind scattered through the voluminous literature that has accumulated. It is believed that the facts now to be laid before the Society warrant a certain broad grouping of doubtful cases which has a practical value.

We must briefly allude to the methods we have adopted, though we make no claim to originality in this respect. The sample of sputum to be examined is of considerable importance. In every case where it was possible we obtained the morning sputum, as it was found that this gives the most trustworthy results. As others have remarked, the sputum expelled on waking in the morning represents the secretions that have accumulated for some hours in the larger air-tubes, and which are comparatively easily voided without hawking, which often results merely in the removal of pharyngeal mucus. A purely mucous sputum rarely yields tubercle bacilli, though exceptions are found to this rule. The most suitable portions for examination are the little opaque strings or fragments which are often to be seen in what at first sight appears 
to be a purely mucous secretion. When the sputum is purulent or muco-purulent the thick whitish yellow pellets should be chosen. Where the sputum contains a large amount of saliva, or where it mainly consists of bronchial secretion, owing to concomitant bronchitis, it is very easy to arrive at a negative result erroneously. On the contrary, in such unfavorable samples of sputum as those just described, it is not unfrequently possible to detect bacilli by a careful selection of suitable portions. A convenient plan is to pour the sputum into a flat glass dish, and examine it against a dark background. Variations in the discharge of the bacilli are not uncommonly met with, and it is well in doubtful cases to examine the sputum at different periods of the day.

The most promising portion having been selected, a small piece is removed with a platinum wire bent into a small loop at one end, a needle, small scalpel, or finepointed pair of scissors, and spread in as thin a layer as possible on the surface of three or four cover-glasses. When the bacilli are likely to be few, or when they have not been previously detected, it is advisable to make preparations from different parts of the same specimen of sputum.

The cover-glasses are allowed to dry, and are then passed through the Bunsen flame in the usual manner, to coagulate the albumin, after which they are stained. After having made trial of various dyes, we find that the sharpest contrast is obtained by staining the bacilli red and the other constituents of the sputum blue, in preference to using a blue or violet stain for the bacilli, and a brown dye for the other elements.

The Weigert-Ehrlich (an aniline solution of fuchsine), or Ziehl's fluid (a carbolic acid solution of fuchsine) were employed for staining the bacilli, and a watery solution of methylene blue was the contrast dye.

In the case of the first solution of fuchsine the specimens were stained for twelve to fourteen hours as a rule, but when Ziehl's fluid was used the time allowed was 
about one hour. In doubtful cases more prolonged staining was employed, and the preparations were heated gently. The ordinary nitric acid solution, 1 part in 3 , was used for decolourising. No alcohol was allowed to touch the specimens, as the staining seemed to be sharper when the excess of the various dyes is removed by washing with water only. After the last washing the cover-glass is allowed to dry, and is then mounted in a drop of Canada balsam dissolved in benzol. A little practice enables one to secure good staining, which greatly facilitates the recognition of the bacilli, especially when their number is very small. For the examination of the preparations, it is absolutely necessary in doubtful cases to have an Abbés or some similar condenser, a one twelfth oil immersion lens, and a very good light. It has frequently happened that specimens of sputum which have been passed by careful observers as containing no bacilli, have been referred to us for further examination, when bacilli have been detected, often in very small numbers. This we believe was mainly due to our invariable adoption of the three precautions just mentioned in all doubtful cases.

It has been asserted that the presence of elastic fibres in the sputum is of more value in diagnosis than the tubercle bacilli. This is entirely at variance with our experience. In many cases of advanced and progressive phthisis it is very difficult and often impossible to find elastic fibres, whereas we have hardly ever failed to find bacilli in simular circumstances, though their number may vary greatly. Apart from the greater facility with which the bacilli may be discovered as compared with elastic fibres, it must be remembered that the expectoration of elastic tissue merely shows that destruction of lung-structure is going on, without giving any information as to the nature of the disease. Tubercle bacilli, on the other hand, are only found when the process is tuberculous. Leyden and others have found that although bacilli may be detected without elastic tissue in cases of phthisis, the latter is never present without bacilli. This statement is 
in accord with our experience. Before proceeding to describe the cases on which our remarks are based, it should be stated that the term "phthisis" is used in the sense of a tuberculous disease, i.e. an infective disease which tends to invade both lungs, and to give rise to specific lesions in other parts of the body.

The cases with which we are more especially concerned may be divided conveniently into five clinical groups :

I. Cases with no physical signs of pulmonary disease.

II. Cases of laryngeal disease of uncertain nature, without definite pulmonary signs.

III. Cases with signs of bronchial catarrh, with or without emphysema.

IV. Cases with physical signs of pleurisy.

V. Cases with physical signs of doubtful import.

(a) Anomalous physical signs.

(b) Apex signs of uncertain nature.

(c) Signs confined to, or most marked at, the base.

A few cases illustrating each group will now be described in brief abstract.

The total number of cases on which the present communication is mainly based, numbering 100 , have been tabulated as shortly as possible, and will be found at the end of the paper.

\section{Cases without Physical Signs. (Total 8.)}

CASE 1.-Mr. P-, æt. 30. Bronchitis a few months previously. Some cough and expectoration since then, with loss of appetite.

General condition good. Pharynx granular and congested. Chest repeatedly examined. No physical signs of disease whatever. The patient was not seen for about twelve months, when he again came under observation, suffering from the same symptoms. The chest was again vOL. LXXI. 
examined with a negative result, and the sputum contained no tubercle bacilli.

As he was going to the seaside, he brought another sample of sputum with him the day before he left town, and on this occasion special attention was directed to the chest, as he complained of a sharp pain in the side. No physical signs were detected, and he left London.

The next day the specimen of sputum was examined, and a few tubercle bacilli were detected.

Two months later, on his return from the seaside, there were subcrepitant râles at both apices, with weak breath-sounds, and the sputum contained a considerable number of bacilli. Physical signs of phthisis became more marked, and the diagnosis was confirmed by several distinguished physicians. The patient wintered at the Engadine without much profit, and on his return the following spring gradually began to fail, and died of confirmed phthisis at the end of last year, eighteen months after tubercle bacilli were first found in the sputum.

CASE 2.-Emily M-, æt. 25. Rheumatic fever ten years ago. Ailing fifteen months since last confinement, with weakness, shortness of breath, slight cough, and expectoration. Five weeks ago she noticed some lumps in her neck, and two weeks later in the right armpit also. The patient was anæmic and very weak. Temp. $102^{\circ}$. Clusters of enlarged glands in the right side of the neck and in right axilla. No glandular enlargement elsewhere. Abdominal organs not enlarged.

No signs of disease of the lungs or heart.

Sputum scanty, and contained tubercle bacilli in small numbers. Two days later the bacilli were found in large numbers.

No physical signs could be detected till a week later, when the breath-sounds were found to be slightly weaker at the right than the left apex, and a small patch of con- 
solidation was discovered in the right interscapular space. These signs gradually cleared up, but a fortnight subsequently some muffled subcrepitant râles were heard at the right supraspinous fossa.

No further change in physical signs has yet taken place. The temperature is irregular, ranging from $102^{\circ}$ to $99^{\circ}$. The appetite and general strength have improved. Patient remains under observation.

CASE 3.-Sarah B-, æt. 27. Winter cough for two years. Ailing for four weeks with cough, slight expectoration, dyspnœa, and wasting. Hæmoptysis on three occasions, not profuse, the first attack four months ago. Nutrition fair. No physical signs.

Bacilli in sputum in small numbers. Sputum almost entirely mucous. A fortnight later bacilli still more scanty. Still no physical signs.

At a third examination a few weeks later no bacilli could be found. Since then the sputum has become so scanty that it is almost impossible for the patient to bring a sample for examination. No marked change has occurred in the general condition, but the resonance at the right supraspinous fossa is now somewhat high pitched, and scanty subcrepitant râles are audible in this region. Patient remains under observation.

II. Cases of Laryngeal Disease of Uncertain Nature, without Definite Pulmonary Signs.

Case 4.-Jesse C-, æt. 51. Previous history good. Six months ago a slight cough developed, and his voice became weak. No emaciation and no dyspnœa. No physical signs in chest.

Larynx: General reddening. Both vocal cords show an irregular, ulcerated surface. No tubercle bacilli found in sputum or in secretion taken from larynx on several occasions. The ulceration gradually healed, but small 
tumours developed in the region of the anterior commissure of the cords. Portions of the growth were removed with laryngeal forceps, but on microscopic examination they were found to consist simply of finely granular necrotic material.

After removal a distinct but small subglottic tumour could be seen below the right cord. A whitish mass was subsequently seen on the upper surface of the left cord. A few months later the temperature rose slightly, the patient complained of pain in the right side, and some crackling râles were heard at the right base in front. Tubercle bacilli were now found in the sputum for the first time. Tracheotomy was performed next day owing to increasing obstruction of the larynx, and the granulations were scraped away as far as possible. Microscopical examination of pieces removed showed merely a finely granular necrotic structure. Tubercle bacilli could now always be detected in the sputum. At a second operation, which became necessary some months later, the growth proved to be tubercular on microscopic examination.

Death twelve months after first symptoms.

Post-mortem.-A small cavity at the apex of the right lung, scattered tubercular nodules below. Recent consolidation and excavation of left apex. Diffuse tuberculous ulceration of the larynx.

CASE 5.-James S-, æt. 60. Ailing six months, with cough and dysphagia. Inspiratory stridor and dyspnœa. Tracheal breathing over the manubrium, faintly heard also at the apex of each lung. Breath-sounds weak.

Larynx: Much swelling of aryepiglottic folds. A small pinkish rounded growth on the internal surface of the left arytenoid cartilage. Vocal cords fixed in the median position, being separated by not more than one sixteenth of an inch.

Diagnosis.-Laryngeal new growth. Infected tracheal glands. Tubercle bacilli were found in the sputum.

Dyspnca became so urgent as to necessitate tracheotomy. Death five weeks after the operation. 
Post-mortem.-Old fibro-caseous patches at the apices of both lungs, and a few small cavities. Miliary tuberculosis of the lower parts. Extensive tubercular infiltration and ulceration of the larynx. A small tubercular tumour springing from the left arytenoid region.

CASE 6.-Thomas D-, æt. 39, hawker, a fairly wellnourished and muscular man. Ailing four months with cough, slight expectoration, hoarseness, and loss of flesh. Inspiratory stridor and dyspnœa. Tracheal breathing over the sternum and weak tubular breathing at both apices. No distinct impairment of resonance. Obscure râles were heard once or twice, now at one now at the other apex.

Larynx : Slight swelling over the arytenoid cartilages, and some irregularity of the interarytenoid fold, from which a small tag-like process projects. Vocal cords fixed in the median position one eighth of an inch apart. Both cords somewhat swollen and granular, their posterior parts coarsely nodulated. No ulceration.

Tubercle bacilli were found in the sputum at four successive examinations. Tracheotomy was performed on account of increasing stenosis of the glottis. Ten days later distinct subcrepitant râles were heard at both supraspinous fossæ. The patient remains under observation.

III. Signs of Bronchitis with or without Emphysema. (Total 15.)

CASE 7. Signs of Bronchitis; hæmoptysis; bacilli detected in the blood expectorated.-Lewis $\mathrm{D}$-, æt. 25, previous health good. Four weeks ago caught cold and cough developed, but he was not laid up at first. Eighteen days later profuse hæmoptysis occurred, and two more attacks of hæmorrhage followed within the next twenty-four hours; over two pints of blood were said to have been lost. Owing to the condition of the 
patient no thorough examination was possible, bubbling râles being heard all over both lungs. Tubercle bacilli were found in the blood which the patient brought up.

On admission to the hospital a few days later, weak breath-sounds with prolonged expiration and occasional crepitation were heard at the left apex.

Physical signs developed rapidly on both sides; bacilli were found in increasing numbers in the sputum, and death occurred twelve weeks after the first hæmoptysis.

Post-mortem.-Scattered caseous nodules in the right lung, extensive recent excavation in the upper part of the left lung and caseous nodules.

CASE 8. Signs of emphysema and bronchitis.-Clara Q-, æt. 25. Cough for six months, slight hæmoptysis. Chest hyper-resonant everywhere, bubbling râles diffused over both lungs. Tubercle bacilli in the sputum in large numbers.

The bronchitis gradually cleared up, but signs of excavation developed at the right apex.

CASE 9. Signs of bronchitis.-George Y-, æt. 42. Winter cough off and on for ten years, continued cough the last twelve months with expectoration and some loss of flesh. Alcoholic tendencies.

The patient was a short, stout, muscular man, with a very fine deep chest. Scattered sibilant sounds and muffled bubbling râles all over the right lung, and at the left base. Pharynx and larynx deeply congested. Sputum muco-purulent, containing a few tubercle bacilli. Three months later there was slight dulness at the right extreme apex with weak breath-sounds, prolongation of expiratory sound, and scanty subcrepitant râles. No change in symptoms; patient thinks he has lost flesh. Still under observation. 
IV. Physical Signs of Pleurisy. (Total 12.)

Cass 10.-George H-, æt. 32. Cough for nine months with slight expectoration and some loss of flesh. Patient very anæmic and looks ill. On the right side dulness from the spine of the scapula to the base, extending laterally to the mid-axillary line. Resonance slightly impaired above the clavicle. An exploratory puncture at the base yielded clear serous fluid. Numerous tubercle bacilli were found in the sputum on several occasions. The fluid became absorbed, but marked signs of phthisis developed in both lungs. The patient was treated by massage and made considerable improvement.

CASE 11.-John E-, æt. 17. "Cold and cough" for six months and pain in the right side. Signs of pleural effusion on the left side reaching up to the third rib. Tubercle bacilli detected in the sputum frequently but in small numbers. The effusion became absorbed and improvement followed. Slight dulness and weak breathsounds at the left base were the only abnormal signs when the patient left the hospital. Four months after his discharge the patient wrote to say he was doing well and was about to go to work.

CASE 12.-Henrietta B-, æt. 36. Cough for three years, worse the last three months and accompanied with pain in the right side. Marked signs of effusion into the right pleura. Three and a half pints of serous fluid were removed by paracentesis. Empyema developed and a free incision was made. The pus contained numerous tubercle bacilli. Death.

Post-mortem.-Empyema on the right side, lung collapsed and containing scanty, softening, fibro-caseous nodules. One nodule immediately beneath the pleura had discharged its contents into the pleural cavity, without any communication between the lung and pleura having 
occurred. Similar nodules and recent miliary tuberculosis in the left lung.

CASE 13.-John M-, æt. 34. Thirteen months ago cough began and was soon followed by hæmoptysis. Physical signs of pleuritic effusion existed on the right side, a few indistinct râles being heard at the apex. Free incision. The purulent fluid removed contained tubercle bacilli. The bacilli could not be detected in the sputum at first, but were afterwards found several times both in the sputum and in the purulent discharge. The wound never healed, and a subsequent operation failed to improve matters. The patient is still alive, three years after the first operation, but his health is failing, and marked signs of phthisis have been present in both lungs for some months.

\section{Physical Signs of uncertain import. (Total 56.)}

(a) Anomalous or indefinite signs.

CASE 14. Signs simulating a localised pneumothorax.Samuel F-, æt. 24. Shortness of breath and wasting for eighteen months. Laid up with " inflammation of the lungs" eight months ago for thirteen weeks. Slight flattening in left subclavian region with hyper-resonance and weak breath-sounds over the whole upper lobe. No other physical signs. Tubercle bacilli in the sputum in fair numbers. The hyper-resonance became more marked over the left upper lobe with almost complete abolition of breath-sounds. No bell-sound to be heard. Breathing less weak at the base. Scanty crackling sounds in the left axilla and rhonchus on the right side.

? Localised pneumothorax, or, a large vomica with obstructed bronchus. Diagnosis quite uncertain.

The sputum, which was scanty, was examined four times but only once contained bacilli.

The patient complained mainly of shortness of breath, 
but was not confined to his bed. No change in physical signs occurred and he was lost sight of.

CASE 15. Signs simulating aneurism.-John L-, æt. 34. No history of syphilis or rheumatism. Fourteen months ago he caught a chill, which was followed by cough, pain in the right shoulder, shortness of breath, and repeated but slight attacks of hæmoptysis. Slight dulness in the first right intercostal space close to the sternum, and to a less extent in the supraspinous fossa. Over this area prolonged expiration, increased vocal resonance, and scanty subcrepitant râles. Distinct pulsation close to the sternum, but no tumour. A short systolic murmur was present in the second space, and the aortic second sound was very loud. Tracheal breathing was heard over the manubrium sterni. The only other abnormal physical signs were dulness and weak breathsounds in the right axilla over the middle lobe.

The sputum was examined three times for tubercle bacilli and twice for elastic tissue with a negative result. At a fourth examination bacilli were found in fair numbers.

The patient improved somewhat and remains under observation.

The dulness now extends rather further outwards under the right clavicle, and tracheal breathing is now only faintly heard over the sternum. Otherwise the physical signs remain unaltered.

CASE 16. Mammary carcinoma, (?) intrathoracic growth. - Harriet M-, æt. 53. Tumour in the right breast for three years. Gradual wasting and cough the last ten months. Carcinoma of right breast well marked. Signs of general pleuritic thickening over the right lung, and doubtful cavernous signs at the lower aspect of the upper lobe in front. Tubercle bacilli in the sputum in very small numbers on two occasions.

The patient was under observation for many months without any change occurring in the physical signs. The 
mammary disease made little or no progress. During her stay in the hospital acute glaucoma developed for which iridectomy was performed, and not long afterwards a strangulated femoral hernia was cured by operation. Nevertheless, when the patient finally left the hospital her condition was better than when she was admitted.

CASE 17. Aneurism of the aorta; secondary tuberculosis. -Richard A-, æt. 36. Gonorrhœa and stricture twenty years ago. Gradually increasing shortness of breath the last twelve months. Face congested. Slight inspiratory stridor. Tracheal breathing over manubrium, with a short systolic murmur and a loud second sound. Breathsounds weaker on right than left side. Larynx and trachea congested. No obstruction visible. Albuminuria.

Diagnosis.-Aneurism of aorta. Stenosis of trachea and right bronchus.

The dyspnœa gradually increased and assumed a paroxysmal character. After some months the question of a "new growth" was raised. Slight impairment of resonance was noted throughout the whole right side without further change in physical signs.

During the last few weeks of his life the patient expectorated with great difficulty a little tenacious brownish-red sputum. The sputum was now examined and found to contain a large number of tubercle bacilli. The existence of pulmonary tuberculosis, which was thus proved, was regarded as a secondary complication not affecting the original diagnosis. Death occurred twelve months after the first examination from failure of the heart following an agonising attack of dyspnœa.

Post-mortem.-A medium-sized, thin-walled aneurism of the aortic arch, compressing the trachea and both bronchi, especially the right. General pleuritic thickening and adhesion over the right lung, with a few small recent cavities in the apex, and tuberculous disease limited to the upper lobe. Granular kidneys. 


\section{V. (b) Apex Signs of uncertain nature. (Total 22.)}

CASE 18. Ulcerative endocarditis, (?) phthisis.-Harriet $\mathrm{P}$ 一, æt. 22. No history of rheumatism. Ailing seven months with cough, expectoration, dyspnœa, and wasting. Systolic murmur in aortic and mitral regions, and a double murmur over pulmonary area. Resonance high pitched at apices of lungs with puerile breathing. Moist crepitation at bases. Bacilli in the sputum.

Some weeks later crepitation became localised at the right supraspinous region. Subsequently signs of excavation appeared at both apices, and the case became further complicated by the development of dry pleurisy, pericarditis, and albuminuria. Irregular pyrexia throughout. Death four months after admission.

Post-mortem.-Ulcerative endocarditis of both sides of the heart, a very small old cavity at the right apex, and a few thin-walled cavities as big as peas, with some small scattered caseous nodules at the left apex.

CASE 19. Oirrhosis and bronchiectasis ; secondary tuberculosis.-Henry F-, æt. 33, lately discharged from the army. Caught cold in Egypt ten months ago from sleeping in a wet bed. Since then cough, profuse hæmoptysis on several occasions, and wasting. Expectoration, offensive almost from the first, coming up in large quantities when he lay on the left side. Signs of consolidation and excavation on the right side from the apex to the fourth rib in front, and at both supraspinous and infraspinous fossæ posteriorly. Bronchial râles under left clavicle. The fœtor of breath was so extreme that the patient had to be removed to a ward by himself. Sputum very profuse and extraordinarily foul. The question was raised as to the advisability of attempting to drain the large cavity by surgical means, but the sputum was found to contain tubercle bacilli, and all idea of an operation was abandoned. 
Diagnosis bronchiectasis, phthisis secondary. Death from exhaustion after some weeks of irregular pyrexia.

Post-mortem.-Localised empyema at right base. Cirrhosis and excavation (? bronchiectatic) of the right lung with general bronchial dilatation and some scattered caseous nodules. Scattered caseous nodules in left lung, but no other disease. Tuberculosis appeared to be a secondary complication.

CASE 20. Enlarged glands simulating lymphadenoma at first. Slight apex signs.-George B-, æt. 41, cough off and on for four years since an attack of typhoid fever. Greatly enlarged glands on the neck, raising the question of lymphadenoma for a time. Patient was a stout muscular man.

Very slight impairment of resonance at both apices with weak breath-sounds and doubtful râles at the right apex, which soon disappeared entirely, the other signs remaining unchanged. Sputum examined three or four times with a negative result; at last a few bacilli were detected. The patient disappeared for eighteen months, but on re-examination no change had occurred in the physical signs (dulness and weak breathing at each apex without râles). The sputum now contained bacilli in fair numbers.

Eight months later the patient had lost ground somewhat and scanty subcrepitant râles were heard at both apices. Still under observation. Cervical glands much smaller.

V. (c) Physical Signs confined to, or most marked at, the base. (Total 16.)

Case 21. Primary tuberculosis of the base.-John W-, æt. 50. Five months ago caught cold, had shivering fits, and was confined to bed for thirteen weeks with pains in the back and side, cough, expectoration, and loss of flesh. 
On admission, respiration was very rapid, and temperature $103^{\circ}$. Lungs generally hyper-resonant with the exception of the posterior bases, where there was slight dulness. At the right base weak breath-sounds with prolonged expiration and diminished vocal fremitus. At the left base tubular breathing and increased vocal resonance. Subcrepitant râles at both apices.

Tubercle bacilli in the sputum. At first their number was not great, but subsequently they were found in abundance.

The patient steadily went down hill, signs of phthisis developed in the upper parts of the lungs, and cavernous signs were detected at both bases.

Post-mortem.-True tuberculous phthisis, originating at the bases of the lungs.

CASE 22.-Oliver D-, æt. 18. Cough for eighteen months, onset gradual. Hæmoptysis soon after cough developed. Expectoration rather profuse and paroxysmal. No fœtor.

The patient was a rather thin, pale lad, but was in fairly good health, and had not lost flesh.

On examination, there was dulness on the right side from the fifth rib downwards, most marked at the base, where there were signs of excavation. No other abnormal signs on either side.

Diagnosis.-Cirrhosis of the lung or basic phthisis. The sputum contained tubercle bacilli in large numbers. It was subsequently ascertained that the patient had been in the hospital a few months previously, when the diagnosis had been "chronic pneumonia."

The patient has improved slightly and remains under observation.

CASE 23. Cirrhosis and bronchiectasis; secondary tuberculosis.-Sydney B-, æt. 10. Cough six years, since an attack of measles. Breath offensive the last three years. Expectoration very foul, and brought up periodically in large "gushes." 
Fœtor of breath extreme, odour faintly fæcal. Fingers clubbed. Slight dulness all over right back, most marked at base; coarse bubbling râles over the whole right lung, with weak breath-sounds. At the base the chest wall is somewhat retracted, and vocal fremitus and resonance are diminished. A few tubercle bacilli in the sputum.

Diagnosis.-Cirrhosis of the lung and bronchiectasis. Secondary tuberculosis. Signs of a cavity developed at the right apex six weeks later, and the general condition gradually deteriorated. The patient left the hospital and died at his home some months later. No post-mortem.

Before proceeding to discuss the conclusions which the above facts suggest, it may be stated that the 100 cases that are narrated represent only a portion of the total number that have been examined. Many other cases might be quoted where doubts as to diagnosis were removed by the discovery of bacilli in the sputum. We have endeavoured to restrict our observations to cases where the diagnosis presented real difficulties. We freely admit that many of our cases were strongly suggestive of phthisis. But it is one thing to suspect the existence of this disease and another to be able to say that it is actually present. Herein lies the great value of examining the sputum.

No negative cases have been included, except when the conclusions have been tested by post-mortem examination. The importance of positive evidence and the comparative worthlessness of negative results in this department of diagnosis can hardly be too much insisted upon. At the same time a negative result after repeated examinations, possesses a certain confirmatory value if it is in accord with the general clinical features of the case. It seems impossible to doubt the significance attaching to the discovery of the tubercle bacillus from a diagnostic point of view. Such facts as those that have been narrated demonstrate the possibility of correctly diagnos. 
ticating many cases where the existence of tuberculosis is masked by certain well-recognised conditions.

Whatever views may be held as to the pathogenic properties of Koch's bacilli, their presence in the expectoration of cases of phthisis and their absence in all other diseases seems hardly to be questioned by anyone now.

It has indeed been stated by G. Zahn that tubercle bacilli were found by him in the sputum of cases of bronchitis in which post-mortem examination demonstrated the absence of tuberculosis. Further details of his cases are wanting, as it has not been possible to obtain his original paper.

Leyden and Ziel suggest that Koch's bacilli may occasionally be found in the sputum of cases of simple bronchitis, especially in hospitals. That is to say, the bacilli may be detected in the bronchial secretions soon after they are inhaled, and before they are destroyed by the action of the living tissues. This of course presupposes that the bacillus is ubiquitous. We have never been able to verify this statement, although numerous cases of bronchiectasis with profuse secretion have been specially examined in this direction, the patients having in many instances been for months in the hospital. In no case where post-mortem examination was mude was tuberculosis proved to be absent when the sputum during life had contained Koch's bacilli.

No constant relation was found to subsist between the number of bacilli expectorated and the severity of the disease. As a rule, bacilli are numerous in acutely progressive cases, but exceptions are not rare. Bacilli are sometimes very scanty when pyrexia is high, whereas in very chronic disease their number may be very large. No definite importance can be attributed to the presence of groups of bacilli; nor can we confirm the statement of Dr. Hunter Mackenzie that the bacilli are always numerous when the tubercular ulceration of the larynx is present. In several well-marked instances of this type bacilli were decidedly scanty. Whether it is necessary 
to assume the existence of a softening process in the lung in all cases where bacilli are expectorated, we are not prepared to say. But in some cases of acute miliary tuberculosis without softening, microscopical examination has revealed minute bacillary ulcers in the bronchioles, which probably discharged some of their bacilli with the expectoration during life. In these cases we had no opportunity of clinical examination. We may perhaps be allowed to repeat that we have no wish to exaggerate the importance of the sputum test, as compared with the method of auscultation and percussion.

Physical examination of the chest is infinitely the more valuable means of diagnosis, but we maintain that cases are not uncommonly met with where this method is found wanting, and may be most usefully supplemented by the investigation of the sputum. This proposition seems to be justified by the facts that have been described.

The difficulty presented by cases where there is a complete absence of physical signs in spite of definite pulmonary and constitutional symptoms, is too well known to need further comment.

The laryngoscopic diagnosis of tuberculous from syphilitic disease of the larynx is at times no easy matter, especially where the physical signs of pulmonary disease are absent or equivocal, and where a well-marked history of previous syphilis is forthcoming. A similar difficulty may arise in the diagnosis of laryngeal tuberculosis from carcinoma. This fact is well illustrated by a case narrated in the 'Lancet' of 1887, where the absence of physical signs, and the appearance of the larynx, seemed to point to epithelioma, and extirpation of the larynx was practised, the patient succumbing a few days afterwards.

In this instance an examination of the sputum would probably have induced the surgeon to prefer tracheotomy to so serious an operation as excision of the larynx.

The uncertain value of auscultation and percussion in severe obstructive laryngeal affections of any description cannot be too strongly insisted upon. In all such cases 
the examination of the sputum has an important bearing not only on diagnosis but indirectly on treatment and prognosis also.

We may briefly allude in the case of pleuritic effusions to the fallacies involved in auscultation of the uncompressed portions of the lung or of the opposite lung, to the uncertain value of pyrexia, and to the fact that complete absorption of the fluid is not incompatible with the presence of pulmonary tuberculosis as illustrating the desirability of some further test.

The fact that phthisis may be completely masked by bronchitis and emphysema should in all suspicious cases of this kind direct attention to the sputum, which will often explain much that would otherwise be obscure.

The last class, to which we would especially direct attention, comprises the large group of cases in which the base of the lung is exclusively or mainly concerned. The diagnosis of simple cirrhosis and bronchiectasis from tuberculous disease is the difficulty that most commonly occurs, but pulmonary abscess, empyema, hydatid disease of the lung or liver, abscess of the liver, mediastinal growths, and other conditions, have all to be considered in individual cases.

The well-known rarity of primary tuberculosis of the base, and the almost invariable presence of apical signs also, will usually, but not always, prevent mistakes being made. Here again the bacillary test is of the utmost importance.

Finally, we would venture once more to emphasize the necessity for great care in the application of this test. Unless the sputum be examined with the precautions that have been alluded to in all doubtful cases, it is better not to examine it at all, lest failure to detect the bacilli should prejudice the conclusions arrived at on other grounds. It may be necessary in special instances to examine the sputum ten or twelve times before a positive result is obtained, but this is the exception. We have only to vol. LXXI. 
add that the bacilli have been found to be of little service for purposes of prognosis.

Complete disappearance of the bacilli from the sputam would of course be a most important element in prognosis if combined with marked improvement of the general condition and physical signs. Unfortunately this concurrence of events is extremely rare. On the other hand, a diminution or increase of the number of bacilli in the sputum possesses little importance when taken alone. For it must be remembered that the number of these micro-organisms found in the sputum is not necessarily a measure of the activity or extent of the disease, but is mainly a question of discharge.

Practically, the prognosis turns on the general condition of the patient more than on anything else, and although the examination of the sputum may corroborate the verdict given on general grounds, it is not of itself of much value.

\section{Summary of Cases.}

Abbreviations. - D.or d. $=$ dulness ; crep. $=$ crepitation; subcrep. $=$ subcrepitant râles; S. S. F. = supra-spinous fossa; T. B. = tubercle bacilli.

The mark * indicates that the case is described more fully in the previous part of the paper.

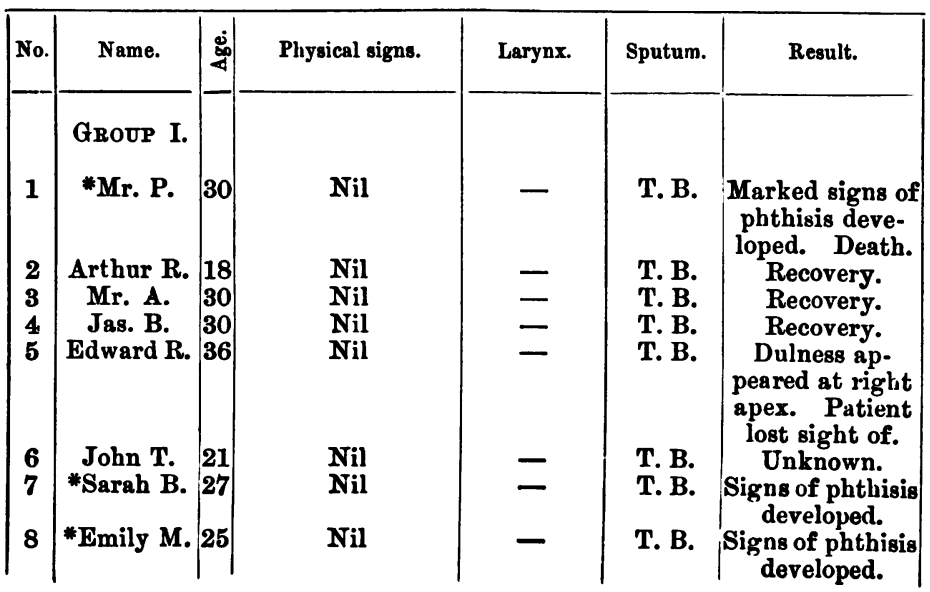


IN CLINICAL DIAGNOSIS.

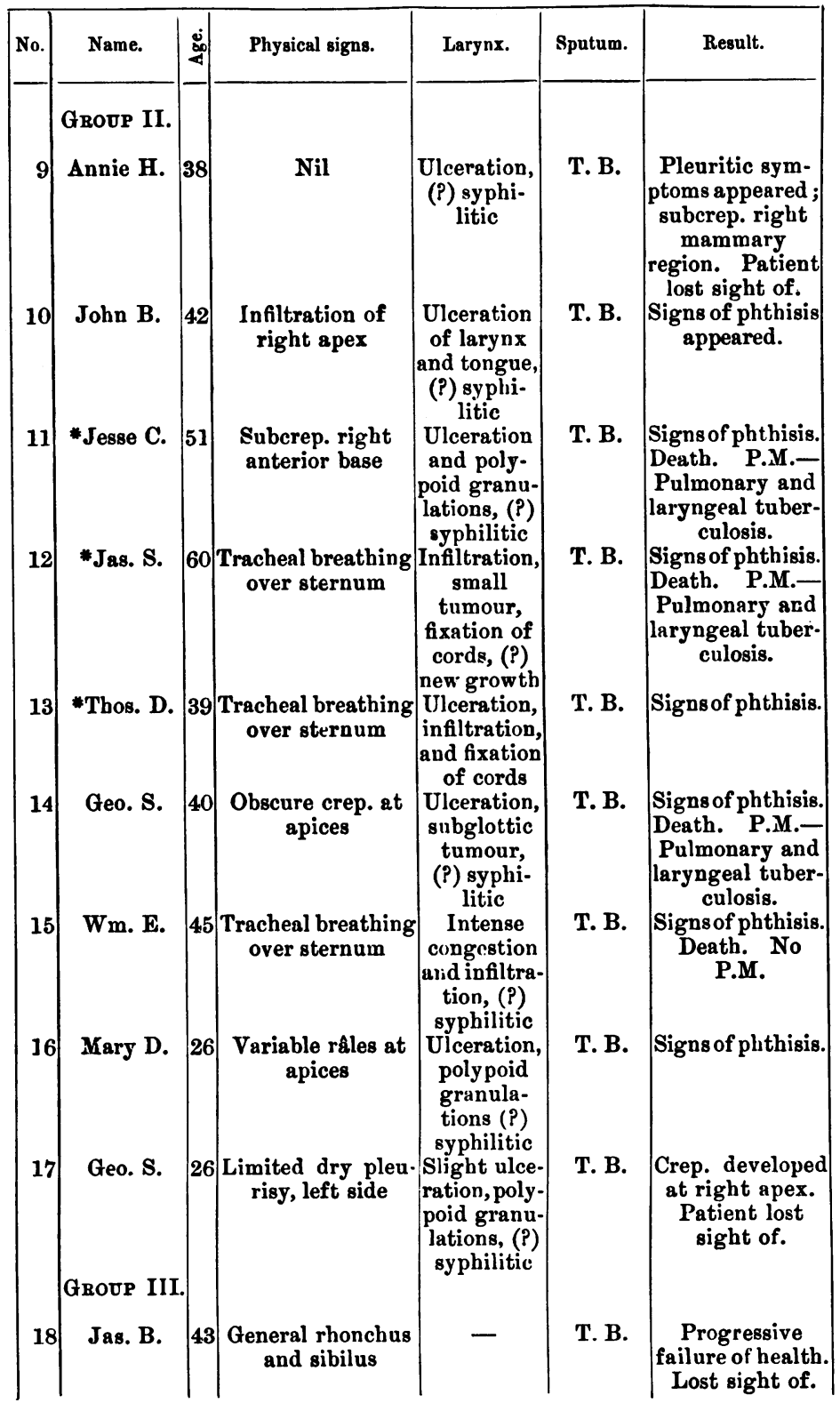




\begin{tabular}{|c|c|c|c|c|c|c|}
\hline No. & Name. & $\frac{2}{4}$ & Physical signs. & Larynx. & Sputum. & Result. \\
\hline 19 & Thos. S. & 37 & $\begin{array}{c}\text { Scattered rhonchus; } \\
\text { obscure râles right } \\
\text { S. S. F. }\end{array}$ & - & T. B. & $\begin{array}{l}\text { Signs } \\
\text { of phthisis. }\end{array}$ \\
\hline 20 & Harry W. & 32 & $\begin{array}{l}\text { Hyper-resonance; } \\
\text { diffused bubbling râles; } \\
\text { slight d. left apex }\end{array}$ & - & T. B. & Lost sight of. \\
\hline 21 & Jas. S. & 62 & $\begin{array}{c}\text { Hyper-resonance; } \\
\text { diffused bubbling râles } \\
\text { left side }\end{array}$ & - & T. $\mathbf{B}$. & Lost sight of. \\
\hline 22 & Thos. H. & 20 & $\begin{array}{c}\text { Hyper-resonance; } \\
\text { scattered rhonchus }\end{array}$ & - & T. B. & $\begin{array}{l}\text { Signs } \\
\text { of plithisis. }\end{array}$ \\
\hline 23 & Chas. H. & 16 & $\begin{array}{c}\text { Hyper-resonance; } \\
\text { slight d. right apex }\end{array}$ & - & T. B. & $\begin{array}{l}\text { Signs of } \\
\text { phthisis; very } \\
\text { chronic course }\end{array}$ \\
\hline 24 & John C. & 25 & $\begin{array}{c}\text { Hyper-resonance; weak } \\
\text { breath sounds ; diffused } \\
\text { bubbling râles }\end{array}$ & 一 & T. B. & Lost sight of. \\
\hline 25 & Annetta G & 34 & $\begin{array}{c}\text { Hyper-resonance; } \\
\text { scattered rhonchus }\end{array}$ & - & T. B. & $\begin{array}{l}\text { Improvement; } \\
\text { signs of emphy- } \\
\text { sema persisted. }\end{array}$ \\
\hline 26 & & 42 & $\begin{array}{c}\text { Scattered sibilus and } \\
\text { bubbling râles }\end{array}$ & $\begin{array}{c}\text { Con- } \\
\text { gestion }\end{array}$ & & $\begin{array}{l}\text { Signs of phthisis } \\
\text { at right apex }\end{array}$ \\
\hline 27 & *Lewis D. & 25 & $\begin{array}{c}\text { Diffused bubbling } \\
\text { râles; patient recovering } \\
\text { from an attack of } \\
\text { hæmoptysis } \\
\text { Hyper-resonance; } \\
\text { diff used bubbling râles }\end{array}$ & $\begin{array}{l}- \\
-\end{array}$ & $\begin{array}{c}\text { T. B. in } \\
\text { blood } \\
\text { expecto- } \\
\text { rated } \\
\text { T. B. }\end{array}$ & $\begin{array}{l}\text { Signs of phthisis. } \\
\text { Death. P.M.- } \\
\text { Pulmonary } \\
\text { tuberculosis. } \\
\text { Signs } \\
\text { of phthisis. }\end{array}$ \\
\hline 29 & Henry C. & 48 & $\begin{array}{c}\text { Hyper-resonance; } \\
\text { diffused bubbling rales; } \\
\text { some fine crep. left apex }\end{array}$ & - & T. B. & Lost sight of. \\
\hline 30 & Mary $\mathbf{H}$. & 40 & $\begin{array}{c}\text { Hyper-resonance; } \\
\text { diffused bubbling râles } \\
\text { and rhonchi }\end{array}$ & 一 & T. B. & $\begin{array}{l}\text { Signs } \\
\text { of phthisis. }\end{array}$ \\
\hline 31 & Samuel K. & 53 & $\begin{array}{c}\text { Hyper-resonance; } \\
\text { slight d. above right } \\
\text { clav.; a few râles at } \\
\text { apices }\end{array}$ & - & T. B. & $\begin{array}{l}\text { Signs } \\
\text { of phthisis. }\end{array}$ \\
\hline 32 & Mr. H. & 47 & $\begin{array}{l}\text { Scattered sibilus ; very } \\
\text { slight d. left apex }\end{array}$ & - & T. B. & $\begin{array}{l}\text { Signs } \\
\text { of phthisis. }\end{array}$ \\
\hline & GroUP IV. & & & & & \\
\hline 33 & *Geo. H. & 32 & $\begin{array}{l}\text { Right pleuritic } \\
\text { effusion; paracentesis ; } \\
\text { serous fluid }\end{array}$ & - & T. B. & $\begin{array}{l}\text { Signs } \\
\text { of phthisis. }\end{array}$ \\
\hline 34 & *John E. & 17 & Left pleuritic effusion & - & T. B. & $\begin{array}{c}\text { Absorptio } \\
\text { fuid. Reco }\end{array}$ \\
\hline 35 & $\begin{array}{c}\text { *Henrietta } \\
\text { B. }\end{array}$ & 36 & $\begin{array}{l}\text { Right pleuritic effusion; } \\
\text { paracentesis; serous } \\
\text { fluid ; empyema } \\
\text { developed }\end{array}$ & - & $\begin{array}{l}\text { T. B. in } \\
\text { pus from } \\
\text { pleura }\end{array}$ & $\begin{array}{l}\text { Death. P.M.- } \\
\text { Tuberculosis of } \\
\text { lung and pleura. }\end{array}$ \\
\hline
\end{tabular}




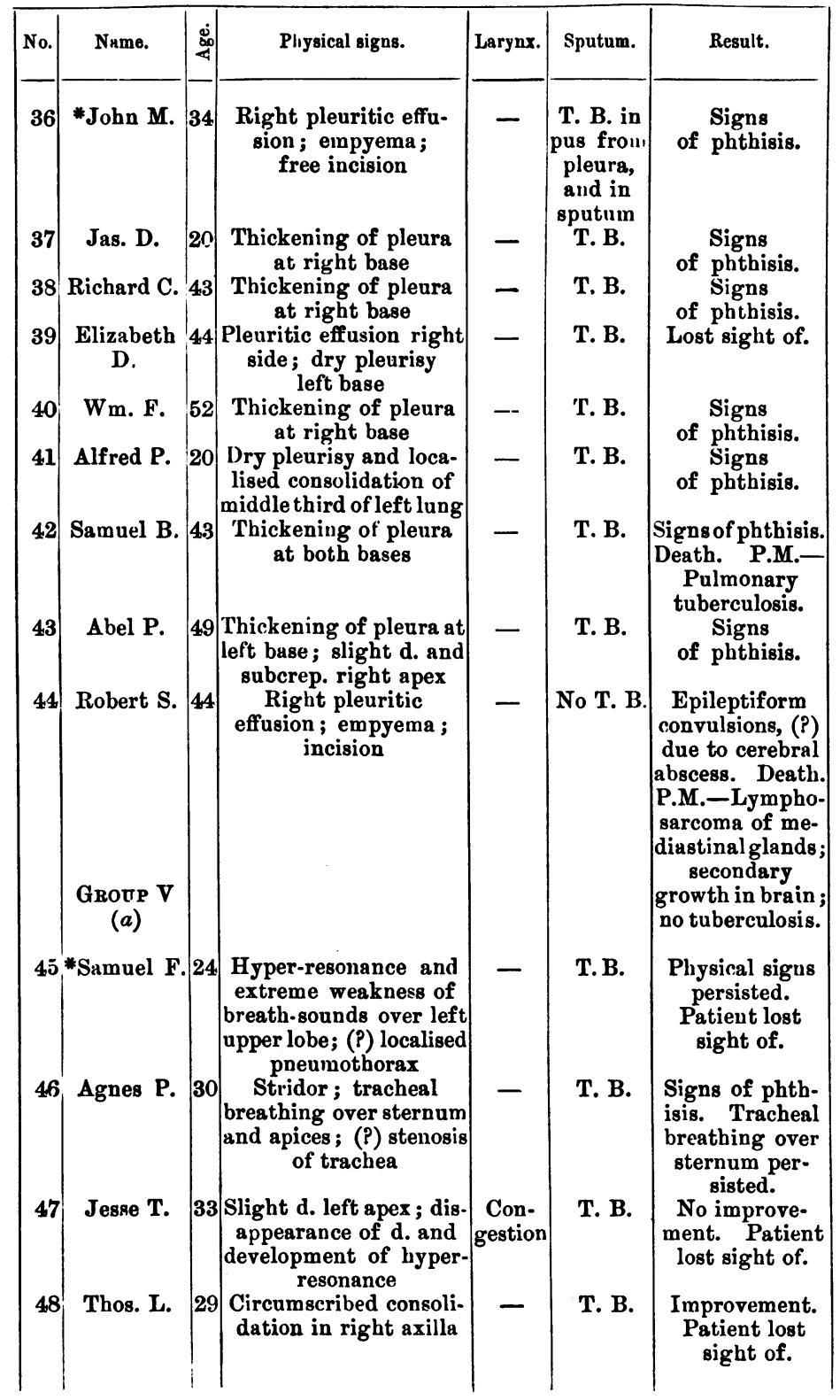




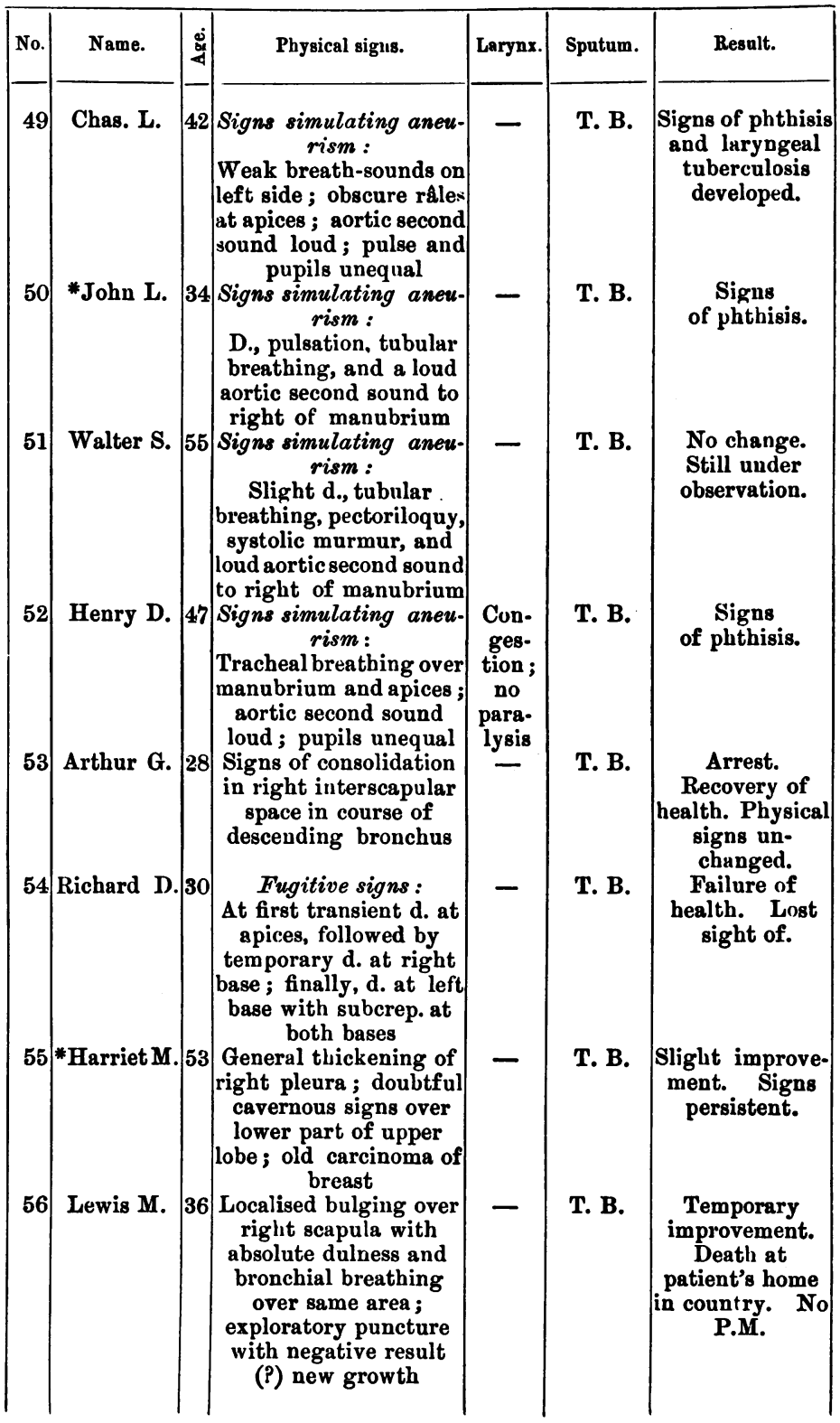




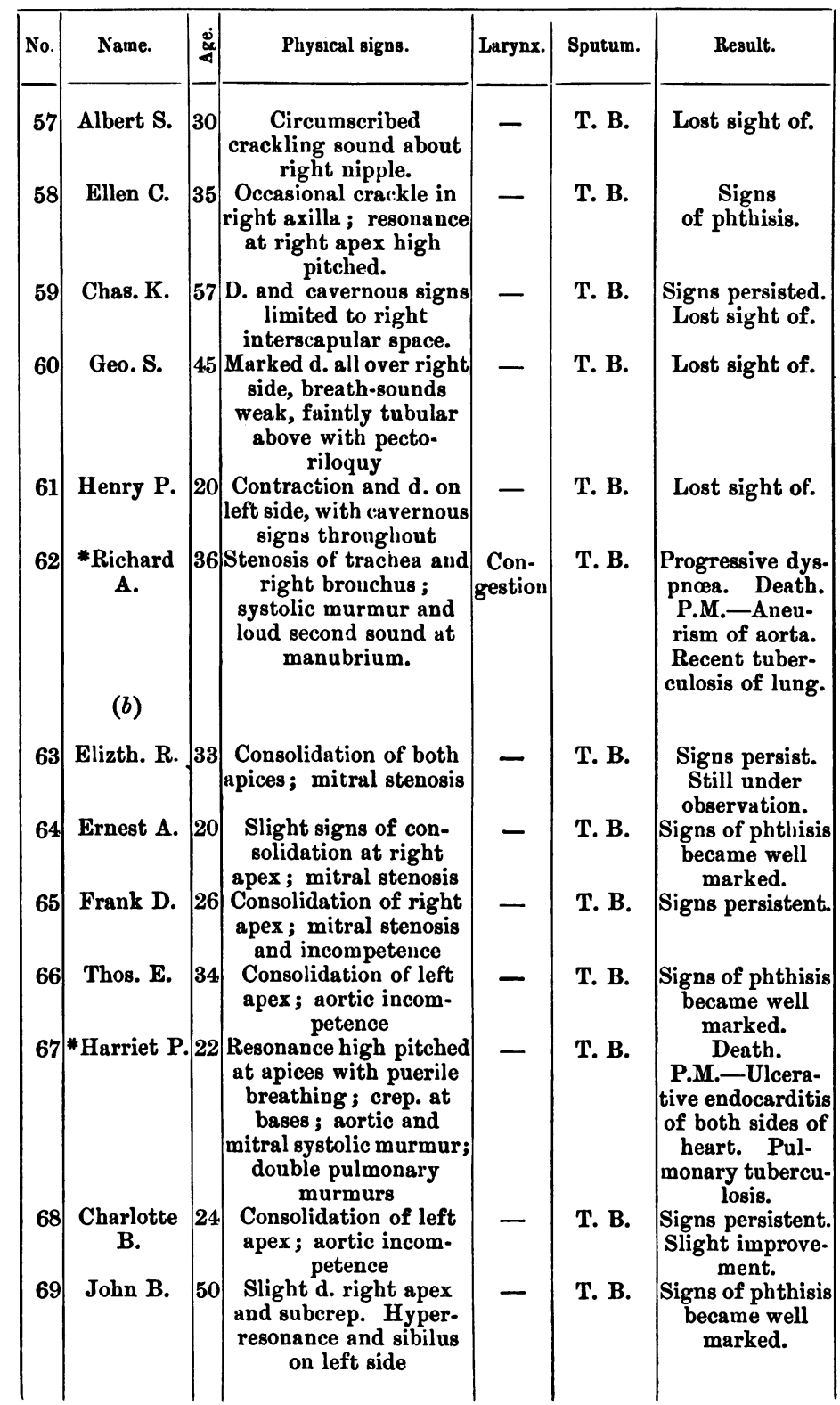




\begin{tabular}{|c|c|c|c|c|c|c|}
\hline No. & Name. & $\left|\begin{array}{l}0 \\
0 \\
8\end{array}\right|$ & Physical signs. & Larynx. & Sputum. & Result. \\
\hline 70 & *Henry F. & 33 & $\begin{array}{l}\text { Consolidation and } \\
\text { excavation of upper } \\
\text { half of right lung. } \\
\text { Diagnosis : bronchiec- } \\
\text { tasis ; phthisis } \\
\text { secondary }\end{array}$ & - & $\begin{array}{l}\text { Very } \\
\text { foul. } \\
\text { T. B. }\end{array}$ & $\begin{array}{c}\text { Death. P.M.- } \\
\text { Cirrhosis and } \\
\text { bronchiectasis } \\
\text { with excavation; } \\
\text { secondary } \\
\text { tuberculosis. }\end{array}$ \\
\hline 71 & Wm. T. & 35 & $\begin{array}{c}\text { Harsh inspiratory and } \\
\text { prolonged expiratory } \\
\text { sound at left apex, } \\
\text { with subcrep. }\end{array}$ & - & T. B. & Lost sight of. \\
\hline 72 & Robert W. & 39 & $\begin{array}{l}\text { Slight d. right S. S. F. ; } \\
\text { breath-sounds weak; } \\
\text { expiration prolonged, } \\
\text { with subcrep. râles }\end{array}$ & - & T. B. & Lost sight of. \\
\hline 73 & Wm. A. & $25 \mid$ & $\begin{array}{l}\text { Slight d. right apex; } \\
\text { prolonged expiration } \\
\text { and subcrep. at } \\
\text { interscapular region }\end{array}$ & - & T. B. & $\begin{array}{l}\text { Signs of phthisi } \\
\text { became marked }\end{array}$ \\
\hline 74 & Martha A. & 32 & $\begin{array}{l}\text { Slight } d \text {. right apex, } \\
\text { with prolonged } \\
\text { expiration and } \\
\text { subcrep. }\end{array}$ & - & T. B. & Lost sight of. \\
\hline 75 & *Geo. B. & 41 & $\begin{array}{l}\text { Very slight d. at } \\
\text { apices, with weak } \\
\text { breathing; greatly } \\
\text { enlarged glands, } \\
\text { suggesting "lymph- } \\
\text { adenoma" }\end{array}$ & - & T. B. & $\begin{array}{c}\text { Signs of } \\
\text { phithisis } \\
\text { developed ; } \\
\text { chronic course }\end{array}$ \\
\hline 76 & Rebecca S. & 26 & $\begin{array}{l}\text { Slight d. at apices } \\
\text { with prolonged } \\
\text { expiration and } \\
\text { subcrep. }\end{array}$ & $\mid \begin{array}{c}\text { Con- } \\
\text { gestiou }\end{array}$ & T. B. & Lost sight of. \\
\hline 77 & Wm. W. & 40 & $\begin{array}{l}\text { Very slight d. left } \\
\text { apex and base, with } \\
\text { weak breath-sounds }\end{array}$ & - & T. B. & Lost sight of. \\
\hline 78 & Wm. S. & 4 & $\begin{array}{l}\text { Very slight d. over } \\
\text { right upper lobe, with } \\
\text { tubular breathing and } \\
\text { pectoriloquy ; no râles }\end{array}$ & - & T. B. & Lost sight of. \\
\hline 79 & David P. & 27 & $\begin{array}{l}\text { Very slight } d \text {. and } \\
\text { weak breathing at left } \\
\text { apex }\end{array}$ & $\begin{array}{c}\text { Con- } \\
\text { gestion } \\
\text { and } \\
\text { infil- } \\
\text { tration }\end{array}$ & T. B. & $\begin{array}{c}\text { Signs of phthisis } \\
\text { became well } \\
\text { marked }\end{array}$ \\
\hline 80 & Edward P. & 27 & $\begin{array}{c}\text { D., weak tubular } \\
\text { breathing, pectoriloquy, } \\
\text { and subcrep. over left } \\
\text { upper lobe }\end{array}$ & - & T. B. & $\begin{array}{l}\text { Two attacks of } \\
\text { hæmoptysis and } \\
\text { gradual failure; } \\
\text { signs unchanged }\end{array}$ \\
\hline 81 & $\begin{array}{c}\text { Benjamin } \\
\text { B. }\end{array}$ & 24 & $\begin{array}{l}\text { Slight d. right apex, } \\
\text { followed by hyper- } \\
\text { resonance, with } \\
\text { blowing breathing and } \\
\text { occasional râles }\end{array}$ & - & T. B. & $\underset{\text { ment }}{\text { Great improve- }}$ \\
\hline
\end{tabular}




\begin{tabular}{|c|c|c|c|c|c|c|}
\hline No. & Name. & 紫 & Physical signs. & Larynx & Sputum. & Result. \\
\hline 82 & $\begin{array}{c}\text { Emmanuel } \\
\text { G. }\end{array}$ & 21 & $\begin{array}{l}\text { Slight d. and subcrep. } \\
\text { at left apex; mitral } \\
\text { systolic murmur }\end{array}$ & 一 & T. B. & $\begin{array}{c}\text { Signs of phthiris } \\
\text { became more } \\
\text { marked. }\end{array}$ \\
\hline 83 & Robert S. & 25 & $\begin{array}{l}\text { Slight d. right apex; } \\
\text { doubtful signs of } \\
\text { excavation ; no râles }\end{array}$ & - & T. B. & $\begin{array}{l}\text { No change in } \\
\text { signs ; lost } \\
\text { sight of. }\end{array}$ \\
\hline 84 & Louisa $\mathbf{H}$. & 27 & $\begin{array}{l}\text { Slight d. and weak } \\
\text { breathing at left apex } \\
\text { obscure râles on cough }\end{array}$ & - & T. B. & $\begin{array}{c}\text { Signs of phthisis } \\
\text { became well } \\
\text { marked }\end{array}$ \\
\hline & (c) & & & & & \\
\hline 85 & *John W. & 50 & $\begin{array}{l}\text { Consolidation of left } \\
\text { base ; thickened } \\
\text { pleura at right base }\end{array}$ & - & T. B. & $\begin{array}{c}\text { Death. P.M.- } \\
\text { Symmetrical } \\
\text { basic tubercular } \\
\text { phthisis. }\end{array}$ \\
\hline 86 & Geo. P. & 21 & $\begin{array}{c}\text { Diffused crep. both } \\
\text { sides; d. over left back; } \\
\text { cavernous signs at base }\end{array}$ & 一 & T. B. & $\begin{array}{l}\text { Death. P.M.- } \\
\text { Phthisis origin- } \\
\text { ating at left }\end{array}$ \\
\hline 87 & Matilda D. & 16 & $\begin{array}{l}\text { Contraction of right } \\
\text { side; d. all over back; } \\
\text { cavernous signs at base }\end{array}$ & - & T. B. & Lost sight of. \\
\hline 88 & Geo. C. & 20 & $\begin{array}{c}\text { Cavernous signs at } \\
\text { right base ; upper parts } \\
\text { free }\end{array}$ & - & T. B. & Lost sight of. \\
\hline 89 & * Oliver D. & 18 & $\begin{array}{l}\text { D., tubular breathing, } \\
\text { pectoriloquy, and coarse } \\
\text { râles at right base }\end{array}$ & - & T. B. & $\begin{array}{l}\text { Signs persistent. } \\
\text { Improvement. }\end{array}$ \\
\hline 90 & Geo. T. H. & 42 & $\begin{array}{c}\text { Thickening of pleura } \\
\text { and consolidation of } \\
\text { lower part of right } \\
\text { lung }\end{array}$ & 一 & T. B. & $\begin{array}{l}\text { Signs persistent. } \\
\text { Slight improve- } \\
\text { ment. }\end{array}$ \\
\hline 91 & & 22 & $\begin{array}{l}\text { D., and cavernous signs } \\
\text { over right lower lobe }\end{array}$ & 一 & & $\begin{array}{l}\text { Signs persistent. } \\
\text { Chronic course. }\end{array}$ \\
\hline 92 & *Sydney B. & 10 & $\begin{array}{c}\text { Flattening at right } \\
\text { base ; slight d. over } \\
\text { right back; coarse râles } \\
\text { and weak breathing. } \\
\text { Diagnosis : Bronchi- } \\
\text { ectasis ; secondary } \\
\text { tuberculosis. }\end{array}$ & 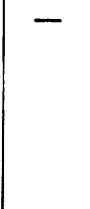 & T. B. & $\begin{array}{c}\text { Cavernous signs } \\
\text { appeared at } \\
\text { right apex. } \\
\text { Gradual failure. } \\
\text { Death at } \\
\text { patient's home. } \\
\text { No P.M. }\end{array}$ \\
\hline 93 & Allan L. & & $\begin{array}{c}\text { Diffused bubbling râles } \\
\text { on both sides ; d. at } \\
\text { both bases with tubular } \\
\text { breathing and pectori- } \\
\text { loquy. Diagnosis : } \\
\text { Bronchiectasis. }\end{array}$ & - & $\begin{array}{c}\text { Very } \\
\text { foul ; } \\
\text { No T. B. }\end{array}$ & $\begin{array}{c}\text { Extreme fotor } \\
\text { of breath. } \\
\text { Irregular } \\
\text { pyrexia. Death. } \\
\text { P.M.-Diffuse } \\
\text { bronchiectasis. } \\
\text { Cirrhosis at } \\
\text { bases. No } \\
\text { tuberculosis. }\end{array}$ \\
\hline
\end{tabular}




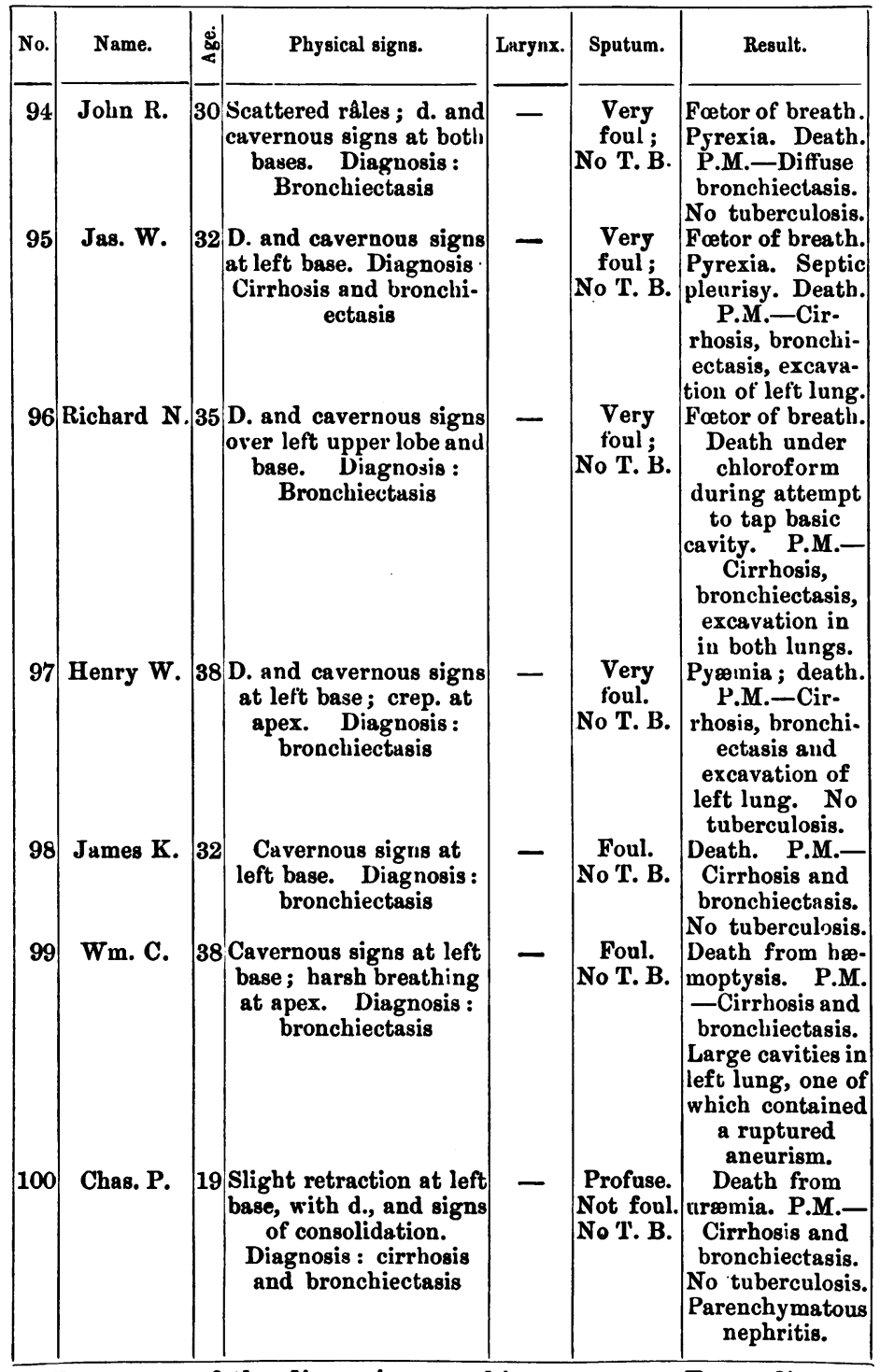

(For report of the discussion on this paper, see 'Proceedings of the Royal Medical and Chirurgical Society,' New Series, vol. ii, p. 395.) 